\title{
O gênero discursivo livroclip: diálogos entre o conto machadiano e o jovem leitor contemporâneo
}

\author{
The discursive genre clipbook: dialogues between the machado's short storie
} and the young contemporary reader

\section{Dioneia Foschiani Helbel}

\author{
Regiani Leal Dalla Martha Couto
}

Sônia Carla Gravena Cândido da Silva

Instituto Federal de Ciência e Tecnologia de Rondônia - IFRO- Ji-Rondônia - Paraná - Brasil

\begin{abstract}
Resumo: Este artigo discute a leitura e a escrita de textos da literatura clássica na contemporaneidade, bem como a possibilidade de abordá-la por meio de gêneros multimodais em sala de aula. Para tanto, apresenta a criação de texto do gênero livroclip a partir do diálogo entre o conto machadiano Missa do Galo e alunos do curso Técnico em Informática do Instituto Federal de Rondônia, Campus Ji-Paraná. O arcabouço teórico foi constituído por estudos que compreendem a leitura e a escrita como fenômenos dinâmicos, inseparáveis da interação social e do contexto histórico e cultural dos sujeitos, como os de Dionísio (2005, 2006), Dell'Isola (2007), Silva (2015),Cani; Coscarelli (2016) e Bakthin (2018). Essa teorização norteou um conjunto de atividades nas quais os alunos compreenderam os papéis sociais dos personagens da obra original, analisaram os discursos, considerando o contexto de produção, para então criarem o gênero digital. Os resultados evidenciaram que os sujeitos compreenderam o contexto de produção, principalmente os enunciados e as relações sociais implícitas e explícitas no conto. Desse modo, ao utilizarem os códigos linguísticos do universo digital e uma linguagem contemporânea, mantiveram a temática principal da obra, o triângulo amoroso, ao mesmo tempo em que se posicionaram como produtores de cultura, fazendo a interlocução entre o autor da obra e outros jovens leitores.
\end{abstract}

Palavras Chave: Leitura. Interlocução. Livroclip.

\begin{abstract}
This article discusses the reading and writing of texts from classical literature in contemporary times, as well as the possibility of approaching it through multimodal genres in classroom.For this purpose, it presents the creation of a clipbook genre text as a possibility of dialogue between Machado's short story titled Missa do Galo and Computer Technician Course students of the Federal Institute of Rondônia in JiParaná.The theoretical framework consisted of studies that include reading and writing as dynamic phenomena, inseparable from social interaction and from the historical and cultural contexts of subjects, such as Dionísio (2005, 2006), Dell'Isola (2007), Silva (2015), Cani;Coscarelli (2016) and Bakthin (2018). This theorization guided a group of activities in which the students understood the social roles of the characters of the original work, analyzed the discourses, considering the production context, and then created the digital genre. The results showed that the subjects understood the production context, especially the implicit and explicit assertions and social relations in the story. Thus, by using the linguistic codes of the digital universe and a contemporary language, they maintained the main theme of the work, the love triangle, at the same time as they positioned themselves as culture producers, making the interlocution between the author of the work and other young readers.
\end{abstract}

Keywords: Reading. Interlocution. Clipbook 


\section{Introdução}

O ensino da leitura pode ainda ser considerado um desafio para as práticas docentes e torna-se ainda mais acentuado quando se trata da leitura literária, especialmente se o assunto são os clássicos da literatura brasileira. Os alunos reclamam do abismo vocabular que os separa dos cânones, da falta de referências culturais e dos enredos incompreensíveis; já por parte da escola, as tentativas para construir pontes que possibilitem 0 acesso e a compreensão desse objeto cultural mais elaborado têm sido insuficientes.

Assim, como na maioria das escolas brasileiras, em Ji-Paraná/RO, local deste estudo, o ensino da Literatura clássica brasileira não tem promovido o diálogo ininterrupto que deve haver entre autor e leitor por meio do texto. Conforme pesquisa realizada com alunos ingressantes do Ensino Técnico Instituto Federal de Rondônia Campus Ji-Paraná IFRO, "suas experiências com a literatura clássica foram frustrantes e traumatizantes, haja vista a repetição de atividades mecânicas e pouco significativas" (COUTO; HELBEL, 2014, p. 76).

Diante disso, este artigo propõe-se a discutir questões referentes a um novo modo de ler e escrever textos da literatura clássica por meio de um livroclip, criado por alunos do $2^{0}$ ano do Ensino Técnico Integrado ao Médio do Instituto Federal de Rondônia, Campus Ji-Paraná, com base na leitura do conto machadiano "Missa do Galo". Para sustentação teórica, filiamo-nos aos estudos que compreendem a leitura e a escrita como fenômenos dinâmicos, inseparáveis do sujeito e seu contexto histórico e cultural, porque partimos do pressuposto de que todo texto emerge como um conjunto de enunciados orais e escritos em um dado momento e espaço histórico, sendo fundamental conhecer o seu contexto de produção.

Dessa forma, consideramos os novos modos de leitura dos alunos, no qual está inserido o objeto de trabalho - o conto Missa do Galo, do autor Machado de Assis - para o percebermos como um objeto da cultura mais elaborada, capaz de mediar o diálogo entre interlocutores (BAKHTIN, 2018), mesmo que em contextos sociais diferentes. Assim, apresentamos uma discussão em torno da mudança nos perfis dos leitores contemporâneos, bem como seus interesses, seus modos de ler, compreender e criar textos, ou seja, de interpretar e produzir discursos por meio de gêneros multimodais. Ademais, apresentamos uma possibilidade de confluência entre uma obra da literatura clássica e os interesses dos jovens leitores, sujeitos da pesquisa.

\section{O gênero livroclip: possibilidades de interlocução entre 0 conto machadiano e 0 leitor jovem}

Os estudos da linguagem reiteram a relevância da leitura e da escrita como ferramentas imprescindíveis para a vida social. Nesse sentido, o texto deve ser tomado como ponto de partida e de chegada para as práticas discursivas, uma vez que é a interação contínua com a escrita que leva o leitor à compreensão do caráter dialógico da linguagem (GERALDI, 2003).

Nessa ótica, tomamos o arcabouço teórico de Bakhtin (2018) sobre o qual nos apoiamos neste estudo, para enfatizar a importância da dialogia entre interlocutores de épocas e contextos diferentes - o leitor contemporâneo e o autor - para a apreensão dos enunciados em um clássico da literatura brasileira do século XIX.

Segundo o autor, para o enunciador constituir seu discurso, leva em conta discursos de outrem presentes no seu. Por isso, todo discurso é atravessado pelo discurso alheio e voltado para as vozes que o circundam. Nessa linha, ao apropriar-se de uma obra clássica por meio do diálogo com o autor, o aluno leitor constitui-se também como produtor de discursos, pois poderá completar, confirmar, como também opor-se às vozes presentes nesse texto (BAKHTIN, 2018).

Para isso, é fundamental que o cânone seja apresentado ao aluno de tal forma que este constitua sentido para sua leitura, e uma das formas para tal é a utilização dos suportes e modos de leitura do 
universo jovem, como a internet e as multissemioses que fazem parte dos gêneros multimodais (CANI; COSCARELLI, 2016).

Para Bakhtin (2018, p. 268), os enunciados presentes nos textos são "correias de transmissão entre a história da sociedade e a história da linguagem" e percorrem um longo e evolutivo caminho, sempre convergente com as esferas de atividade humana. Isso nos assegura que a modificação ou a permanência dos valores sociais em determinado período histórico, bem como da cultura historicamente produzida, influenciam os modos de leitura e o interesse pelos objetos culturais sendo, na questão em foco, uma obra clássica da literatura brasileira - o conto machadiano.

Ainda cabe ressaltar o papel das tecnologias, principalmente o da internet, para possibilitar a transposição de barreiras de tempo e espaço entre a literatura clássica do século XIX e jovens leitores contemporâneos, uma vez que seu uso não é mais entendido como opção, mas como demanda social que deve fazer parte das atividades de ensino na escola.

Ao abordar a leitura nas telas, principalmente de aparelhos móveis, Arena (2015) explica que há uma espécie de ruptura nas estratégias de leitura em relação às adotadas nos suportes convencionais, como no livro impresso, uma vez que "as condutas que compõem o perfil do leitor que lida com as telas já não são as do papel, por isso as ações que compõem os atos de ler terão de ocupar seu lugar nessa área de ensino" (ARENA, 2015, p. 119). Associamos o que defende o autor com a leitura literária canônica ao acreditarmos que a utilização de novos suportes e gêneros pode possibilitar que 0 aluno se aproxime dessas obras, consideradas por eles muito "complexas, difíceis, chatas, longas, e distantes" (COUTO; HELBEL, 2014, p. 79) da realidade contemporânea, especialmente em função da linguagem e do contexto em que foram produzidas.

Diante dessas reflexões, há que se falar sobre alguns textos, muito comuns nas práticas sociais cotidianas - os multimodais - cujo significado se realiza por mais de um código semiótico (KRESS; VAN LEEUWEN, 1996), centralizado não apenas na escrita, mas constituído também por imagens e diferentes tipos de informação. O texto multimodal, comum em suportes como tela da televisão, do cinema e do computador, não exige linearidade. Embora toda leitura possa também ser considerada como não linear, pois o leitor pode fazer múltiplas conexões, no texto convencional as palavras vêm umas depois das outras, assim como os parágrafos e os capítulos. Já os textos ancorados pela multimodalidade são mais abertos aos percursos de leitura escolhidos pelo leitor.

No contexto dos gêneros multimodais, o livroclip é uma possibilidade de aproximação do jovem leitor com as obras clássicas da literatura brasileira. Esse gênero é essencialmente multimodal, porque se constitui de fotografias, sons eletrônicos, imagens fragmentadas em movimento, colagens, documentário, vídeo biográfico, animação com bandas famosas, game e publicidade e pode ser entendido como o clipe de um livro. É entendido como

o clipe de um livro, ou seja, vídeo para apresentação de uma obra qualquer, com imagens visualmente interessantes, com uso de trechos da obra e também inclusão de uma trilha sonora, composta por músicas diversas. Por ser fruto de computação gráfica, consideramos o livroclip como um gênero digital, que nasceu e se consolidou nesse meio (DINIZ; GRANDE, 2013, p.150).

Vários autores, como Coscarelli (2016), abordam sobre a leitura dos gêneros multimodais, mas quando se trata da elaboração/criação desses textos por alunos, os estudos ainda precisam ser aprofundados. Portanto, o livroclip pode ser usado como material didático para incentivar a leitura de obras literárias e científicas, todavia é importante que os alunos aprendam a escrevê-lo, utilizando tecnologias de criação de filmes, como o Windows Live MovieMaker (Bitencourto; Delgado 2011). As autoras acrescentam que a criação do livroclip pelos alunos pode auxiliar na aprendizagem de literatura e de outras áreas, uma vez que é um gênero de grande apelo visual, lúdico, atraente, que pode despertar o interesse pela leitura e o desejo de se aprender mais sobre o assunto revelado na animação. 
Silva (2015) também destaca a importância de os próprios alunos criarem o livroclip, pois isso lhes possibilita (re)ler e (re)criar uma obra e, a partir dela, assumir o papel de coautor do texto lido. Comungamos com a autora, pois acreditamos que esse diálogo permite ao aluno a constituição de sentidos para uma obra da literatura clássica e a apresentação do texto original numa versão moderna com recursos do ambiente digital. Assim, ao mesmo tempo em que busca elementos de referência no tempo presente, não exclui o sentido original, mas relaciona o atual com o tempo futuro.

Dessa forma, os recursos oferecidos pelo gênero livroclip podem contribuir para a aproximação dos alunos com obras da literatura brasileira, como os contos de Machado de Assis, pois ao transitar entre a interpretação desses clássicos, no suporte impresso, e o novo formato de um gênero contemporâneo, não só se apropriarão dos elementos caracterizadores dos dois gêneros - composição, conteúdo e estilo (BAKHTIN, 2018) - como também serão protagonistas no processo de leitura, elaboração e reelaboração, construindo-se como sujeitos autores, que dialogam e interagem, a fim de responder ativamente ao novo gênero.

\section{Metodologia}

O estudo insere-se na pesquisa-ação e teve como sujeitos alunos do $2^{\circ}$ ano A do Ensino Técnico do Instituto Federal de Rondônia,Campus Ji-Paraná, a quem propusemos uma oficina com duração de vinte horas para a criação de livroclips, a partir de um conto do autor Machado de Assis, em seus formatos mais diversos: fotografias, sons eletrônicos, imagens fragmentadas em movimento, colagens, documentário, animação com bandas famosas, game e publicidade. A criação de livroclip a partir de uma obra literária, segundo Martins (2009), apresenta ao aluno possibilidades de significação desse gênero enquanto objeto artístico e polissêmico que transgride convenções e envolve o leitor num jogo de descobertas e redescobertas de sentido.
A opção pelos contos desse autor se deve ao fato de que, assim como Saraiva (2007), considerarmos relevante que a obra machadiana seja apresentada aos alunos, pois suas narrativas, ainda que escritas no século XIX, podem provocar o diálogo com leitores contemporâneos, uma vez que "transpõem uma dimensão do humano que transcende um tempo e um espaço determinados" (SARAIVA, 2007, p.174).

Posteriormente ao trabalho com a leitura do conto "A Cartomante", que envolveu discussões sobre a biografia do autor, o contexto de produção, os temas presentes na obra, bem como a composição e o estilo adotado pelo autor, os estudantes, divididos em grupos, escolheram um conto do mesmo autor e uma das modalidades de livroclip para realizarem operações envolvendo "a passagem de um texto escrito para outro texto escrito, especificamente, de um gênero textual para outro gênero textual" (DELL'ISOLA, 2007, p. 38).

A tarefa foi, então, transformar um texto narrativo, em um novo gênero, cujo modo de leitura possibilitaria a ruptura da linearidade. Esclarecemos que não compreendemos o termo "retextualização" (DELL'ISOLA, 2007), apenas como uma operação dos elementos linguísticos na superfície textual, mas como uma atividade epilinguística, conforme Geraldi (2003), com o fito de proporcionar aos alunos a reflexão sobre os recursos expressivos da língua para a composição do gênero em questão.

Para a atividade de retextualização, enfatizamos aos alunos a necessidade de ler os contos e compreendê-los em seu contexto de produção para constituir sentido e criar um novo texto que dialogasse com leitores jovens. Para tanto, elaboramos atividades sobre os dois gêneros, o conto machadiano e o livroclip.

Essas atividades, organizadas em módulos não lineares, contemplaram, principalmente, a formação do pensamento teórico sobre os dois gêneros, bem como a leitura e a escrita como prática social, e ainda o acesso a plataformas online e softwares para serem usados na criação/elaboração e reelaboração do livroclip. A cada módulo, avaliamos 
coletivamente as atividades, propondo novos desafios.

Ao final do conjunto de atividades, os alunos criaram doze livroclips, os quais, após passarem pela fase de reelaboração, por meio de ações interlocutivas de correção entre as pesquisadoras e os sujeitos, foram divulgados na Mostra de Livroclips que ocorreu no auditório do campus. Selecionamos um desses trabalhos para apresentar neste artigo, tendo como critério de escolha o fato de as autoras terem se tornando protagonistas do processo de criação ao adotarem posturas ativas quanto à produção de discursos situados historicamente.

\section{Análise e discussão dos dados}

O livroclip apresentado neste estudo foi produzido por duas alunas, cujo desinteresse pela obra foi justificado por elas pela alta complexidade, sem, no entanto, terem lido um único texto de Machado de Assis. Esclarecemos que a necessidade em ler $o$ conto surgiu timidamente $e$ foi se intensificando à medida em que as atividades, principalmente as que privilegiaram questões enunciativas, se realizavam.

Essa rejeição ao autor por alunos do Ensino Médio já foi constatada em outros estudos, como os de Saraiva (2007), os quais apontam que, mesmo não conhecendo as obras machadianas, os alunos as rotulam de forma negativa. Salienta o autor que "Raros são os alunos que já leram algum de seus textos; entretanto, muitos dizem ser ele um autor 'difícil e chato', ainda que não tenham tido acesso às suas obras" (SARAIVA, 2007, p. 173).

Para criar o livroclip a partir do conto Missa do Galo, as alunas utilizaram a plataforma online PowToon, que permite a criação de apresentações na forma de slides e vídeos animados. Por questões didáticas, optamos por analisar alguns trechos, em três planos, conforme a sequência estrutural do conto clássico, bem como apresentar uma sinopse para orientar o leitor deste artigo.

O conto Missa do Galo é narrado de forma retrospectiva pelo personagem Nogueira que, já adulto, relata um acontecimento do passado. $\mathrm{O}$ enredo se desenvolve quando ele tem dezessete anos e vai para o Rio de Janeiro para estudar. Lá, mora na casa do escrivão Meneses. O autor faz um recorte temporal e explica que o jovem, mesmo em férias escolares, permanece na Corte a fim de assistir à Missa do Galo na noite de Natal.

O escrivão Meneses, mesmo casado com dona Conceição, uma santa, segundo o narrador, mantém um caso extraconjugal com uma mulher separada do marido. Na casa, todos sabem, inclusive a esposa. Uma vez por semana, Meneses encontrase com a amante. A noite de Natal é uma dessas ocasiões. Mesmo sendo descrita inicialmente como uma santa, Conceição vive em circunstâncias favoráveis para que ela também pense em cometer adultério. Assim, planeja um encontro, ao que tudo indica, com o jovem Nogueira, enquanto este espera a hora da Missa do Galo na sala da casa de Conceição. Ele por ingenuidade e inexperiência, não chega a captar exatamente as intenções de Conceição. No entanto, nenhum envolvimento explícito acontece com eles. Nogueira conta no final que, no ano seguinte, o escrivão Meneses morre de apoplexia. Quanto à Conceição, casa-se novamente logo depois.

A narrativa original é escrita em primeira pessoa, por Nogueira, um jovem que sai do interior do Rio de Janeiro para estudar na capital e inicia relatando suas percepções sobre um fato ocorrido. $\mathrm{O}$ escritor situa temporalmente o leitor por meio de uma referência - o período de Natal em 1861 ou 1862. Vejamos.

Nunca pude entender a conversação que tive com uma senhora, há muitos anos, contava eu dezessete, ela trinta. Era noite de Natal. Havendo ajustado com um vizinho irmos à missa do galo, preferi não dormir; combinei que eu iria acordá-lo à meia-noite. A casa em que eu estava hospedado era a do escrivão Meneses, que fora casado, em primeiras núpcias, com uma de minhas primas a segunda mulher, Conceição, e a mãe desta acolheram-me bem quando vim de Mangaratiba para o Rio de Janeiro, meses antes, a estudar preparatórios (ASSIS, 2004, p. 386).

Entretanto, as autoras do livroclip optam por mudar a ordem e o foco narrativo, assumindo o lugar 
de Nogueira e apresentando, inicialmente, as suas personagens para, posteriormente contar a história. Assim, nas três telas iniciais, mesclam trechos do conto original com suas percepções a respeito de Nogueira, Conceição e Meneses. É o que mostram as figuras 1,2 e 3.

Figura 1: Descrição do personagem Nogueira.

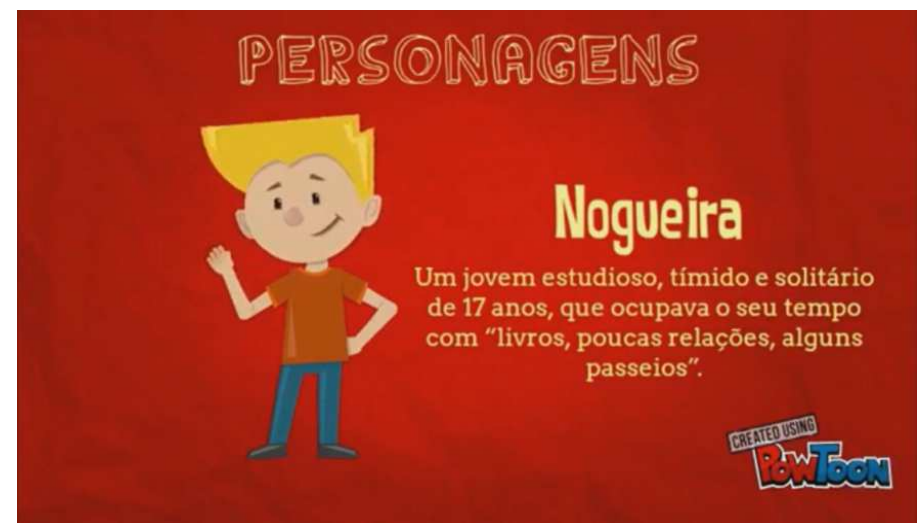

Fonte: Dados da pesquisa.

Figura 2: Descrição do personagem Conceição.

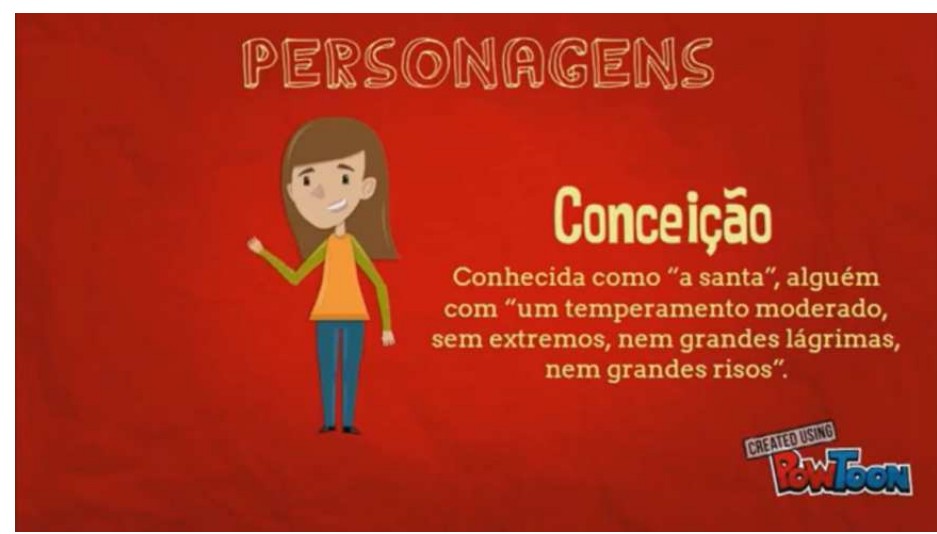

Fonte: Dados da pesquisa.

Figura 3: Descrição do personagem Meneses.

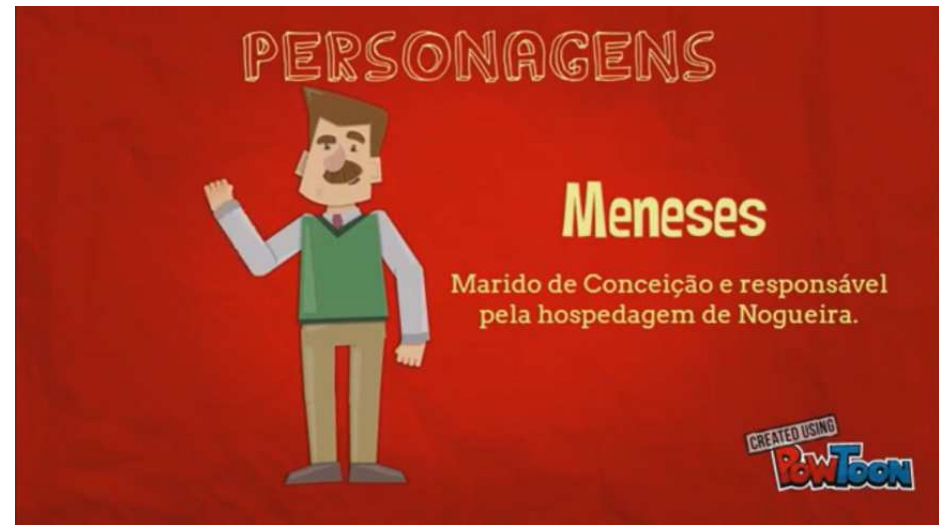

Fonte: Dados da pesquisa.
Chamamos a atenção para a forma como os personagens são apresentados: no início do livroclip e em sequência. A narrativa original, que inicia com o narrador personagem Nogueira já adulto, relatando uma história da juventude e descrevendo os personagens, paulatinamente ao longo do conto, é alterada. As alunas dialogam com Machado de Assis e Nogueira e posicionam-se de outra forma. Questionando as alunas sobre essa mudança, nos disseram que a interlocução com o público leitor do livroclip poderia ser "mais instigante" e dinâmica.

Colocando-nos como leitoras do texto retextualizado, concordamos que a apresentação das personagens sem vínculo explícito entre si pode levar - leitor a hipotetizar sobre as relações entre as personagens e a continuar a leitura para confirmar ou refutar suas ideias. Não sabemos, por exemplo, que Conceição é esposa de Meneses, nem que Nogueira é parente dele. Essa mudança leva a crer que as alunas atuaram sobre 0 conto e tornaram-se protagonistas no processo de leitura, constituindo-se também como autoras ao replicarem as vozes presentes no conto (BAKHTIN, 2018).

$\mathrm{Na}$ sequência, a Figura 4 informa sobre a relação entre duas personagens: Nogueira é hóspede de Menezes, mas o leitor não sabe ainda, com certeza, o papel de Conceição.

Figura 4: Trecho narrativo.

\section{Nogueira vai estudar no Rio} de Janeiro e se hospeda na casa do escrivão Menes: un parente distan

\section{Fonte: Dados da pesquisa.}

Nesse momento, o narrador se materializa na tela por meio da imagem animada de uma mão, que vai escrevendo o texto, sobre um fundo vermelho, da esquerda para a direita. Destacamos, nessa tela, a 
nosso ver, um interessante recurso para a linguagem multimodal: o movimento da escrita.

Dionísio (2005) postula que a multimodalidade refere-se às diferentes formas e modos de representação utilizados na construção linguística, tais como: palavras, imagens, cores, formatos, marcas/ traços tipográficos, disposição da grafia, gestos, entre outros para constituir enunciados. Ao provocar o leitor para a leitura do texto simultaneamente à escrita, as autoras também possibilitaram uma aproximação maior entre o leitor do livroclip e a história narrada por Machado de Assis, com o intuito de propor uma interação com o conto. Importante observar que algumas informações sobre Meneses são adicionadas e isso confirma ou refuta hipóteses que podem ter sido levantadas pelo leitor do livroclip a partir das telas de apresentação dos personagens.

A Figura 5 apresenta mais um trecho narrativo. Ao acompanhar o movimento da mão do narrador, o leitor descobre que Menezes é infiel à sua esposa. Essa informação provoca-o a fazer a ligação entre duas personagens: Menezes, o traidor, e Conceição, a submissa esposa traída.

Figura 5: Trecho narrativo.

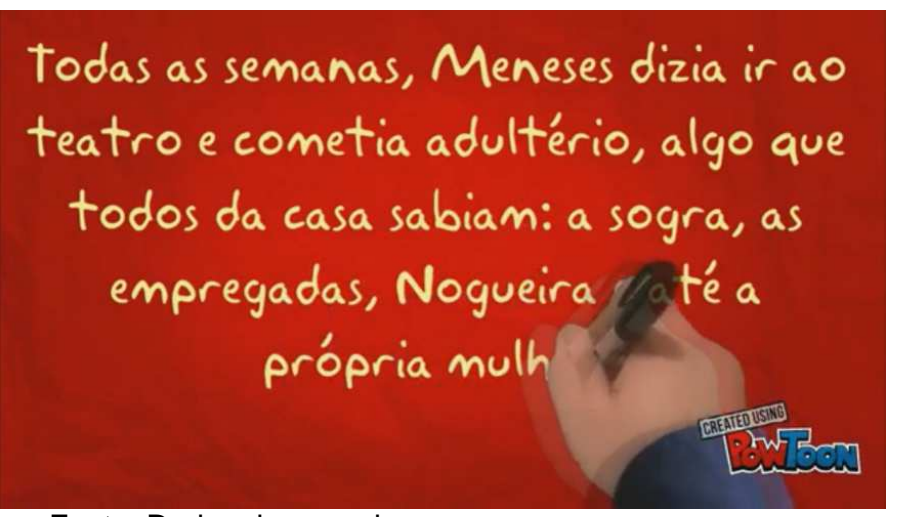

Fonte: Dados da pesquisa.

O trecho apresentado foi criado a partir do fragmento do conto machadiano:

Nunca tinha ido ao teatro, e mais de uma vez, ouvindo dizer ao Meneses que ia ao teatro, pedi-lhe que me levasse consigo. Nessas ocasiões, a sogra fazia uma careta, e as escravas riam à socapa; ele não respondia, vestia-se, saía e só tornava na manhã seguinte. Mais tarde é que eu soube que o teatro era um eufemismo em ação. Meneses trazia amores com uma senhora, separada do marido, e dormia fora de casa uma vez por semana. Conceição padecera, a princípio, com a existência da comborça; mas afinal, resignara-se, acostumara-se, e acabou achando que era muito direito (ASSIS, 2004, p. 386).

Mais uma vez, as alunas autoras entenderam a necessidade de adaptação da linguagem a um suporte, que já não é mais o livro, para torná-la adequada ao gênero livroclip. Corroboramos as ideias de Compagnon (2001) quando explica que o texto literário, no caso o conto machadiano, vincula-se aos leitores de sua época de produção e ao seu contexto de origem, mas é anacrônico, em outras palavras, ultrapassa as barreiras temporais. Assim, as alunas atualizaram a obra a partir da referência ao seu próprio contexto, em especial do linguístico, eliminando e substituindo expressões que poderiam causar dificuldade de compreensão aos leitores, como "as escravas riam à socapa", "Meneses trazia amores com uma senhora", "Conceição padecera com a existência da comborça". Ao transformarem a linguagem, possibilitara ma aproximação entre os leitores jovens e o conto original.

Para reforçar o adultério, na Figura 6, as alunas apresentam uma situação comum ao contexto de produção da obra: a mulher passiva diante do comportamento machista e desonesto do esposo.

Figura 6: Traição de Meneses.
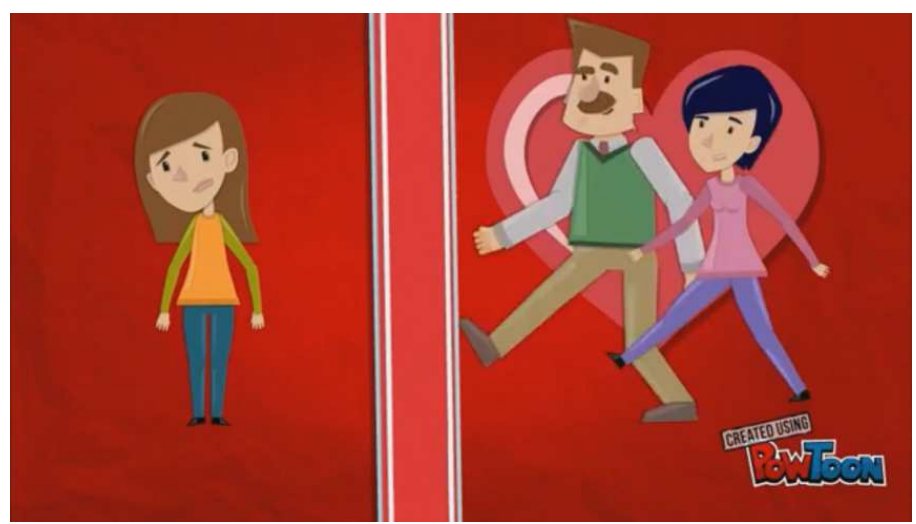

Fonte: Dados da pesquisa.

Inferimos que a compreensão dos temas centrais do conto, como a traição e o papel da mulher no século $X I X$, possibilitou às alunas o que Bakhtin (2018) chama de responsividade. Em outras palavras, deram uma resposta ativa às vozes de Conceição de 
Menezes, interpretados por elas por meio da figura estática e triste de Conceição, opondo-se às de Menezes e da amante, animadas por movimentos rápidos, como se tivessem caminhando felizes. A construção dessas imagens contribui para que o leitor reflita sobre os comportamentos das personagens e tome partido, já no início da história.

Os recursos semióticos dessa cena mostram muito mais que um enredo; revelam aspectos culturais importantes para o leitor compreender os comportamentos humanos dos séculos XIX e XXI. O movimento dialógico, a partir da negociação de sentidos, provocou uma diferente interpretação por meio da expressão de Conceição que, para as autoras do livroclip, não suportava tão facilmente a traição do marido, como apresentado originalmente, dada sua expressão triste, na Figura 6. Sobre isso, pensamos que a partir dos papéis sociais das personagens, as alunas puderam refletir também sobre os seus, inclusive nos de mulheres que lutam pela igualdade de gêneros, e de autoras do livroclip.

Essa compreensão, segundo Bakhtin (2018), consiste em um processo dialógico, pelo fato de um texto poder possibilitar o encontro dos leitores com outros contextos. Esse movimento possibilita ao leitor a ampliação do seu universo de compreensão e, nesse movimento convergente, entre o conhecimento novo e o anterior, o processo dialógico ocorre.

Como já dissemos, para o autor, o processo de compreensão consiste em "opor à palavra do locutor uma contra palavra" (BAKHTIN, 1996 p.105). Portanto, espera-se que nos processos dialógicos os interlocutores assumam uma postura ativa por meio de respostas. Tais respostas são o resultado de uma postura ativa do interlocutor que, por sua vez, ao compreender as enunciações elaboradas pelo locutor, assume uma postura de sujeito.

Posteriormente, o narrador conta que o jovem lê um romance enquanto espera pela companhia de um vizinho para irem à Missa do Galo, o que deixa transparecer aspectos da sua cultura e da sua índole: o bom moço. Assim, a Figura 7 retrata esse diálogo.
Figura7: Diálogo entre Conceição e Nogueira.

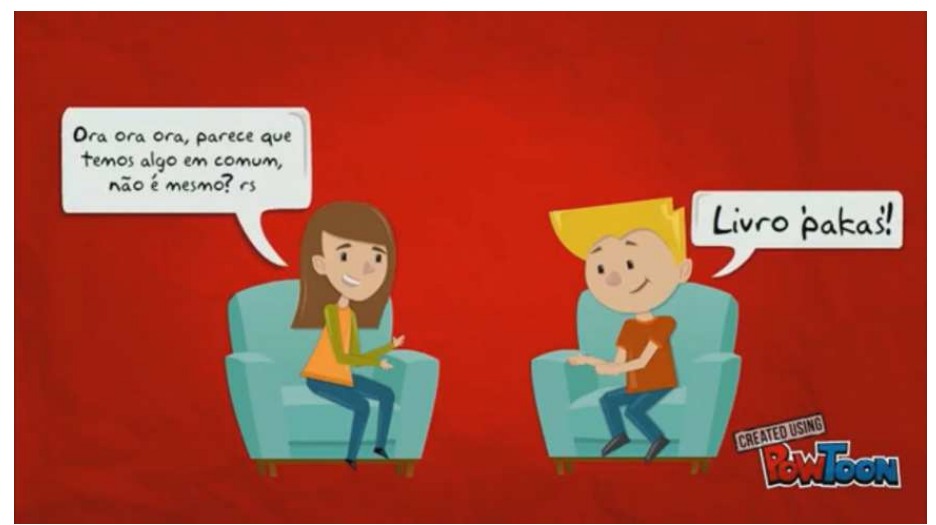

Fonte: Dados da pesquisa.

Conceição, mais uma vez abandonada pelo marido, surge na sala e os dois começam a conversar. Ela já não parece tão tímida e submissa, pois inicia o diálogo e sorri enquanto conversam animadamente.

O narrador, pela primeira vez abre espaço para os personagens conversarem e o faz por meio de balões, como em uma história em quadrinhos. Importante salientar a informalidade linguística que pode ser constatada pela fala de Nogueira: "Livro pakas". Podemos apontar a expressão onomatopaica "rs" na fala de Conceição, comum nas interações por Whatsapp, denotando um riso irônico, e a palavra "pakas" como um enunciado produtor de sentido, utilizado pelas autoras para a marcação do seu estilo que, para Bakhtin (2018), é resultante de uma visão de mundo. Ao empregá-la, consideraram os recursos linguísticos à disposição do enunciador, pensando, principalmente, no interlocutor do livroclip.

Dessa forma, a nova linguagem tornou o texto atual sem, no entanto, excluir ou modificar o seu sentido original. Ao adaptar a linguagem tendo como referência o aqui e o agora, as alunas conseguiram fazer uma ponte entre o ontem e o hoje, isto é, entre a obra de Machado de Assis e o público da Mostra de Livroclips.

Percebemos a autonomia de leitura e de escrita das autoras do novo gênero postulada por Zilberman (2001), pois assumem a atitude de coautoras do texto ao intervirem em um campo que antes pertencia apenas a Machado de Assis. Essa coautoria continua na Figura 8: 
Figura 8: Diálogo entre Conceição e Nogueira.

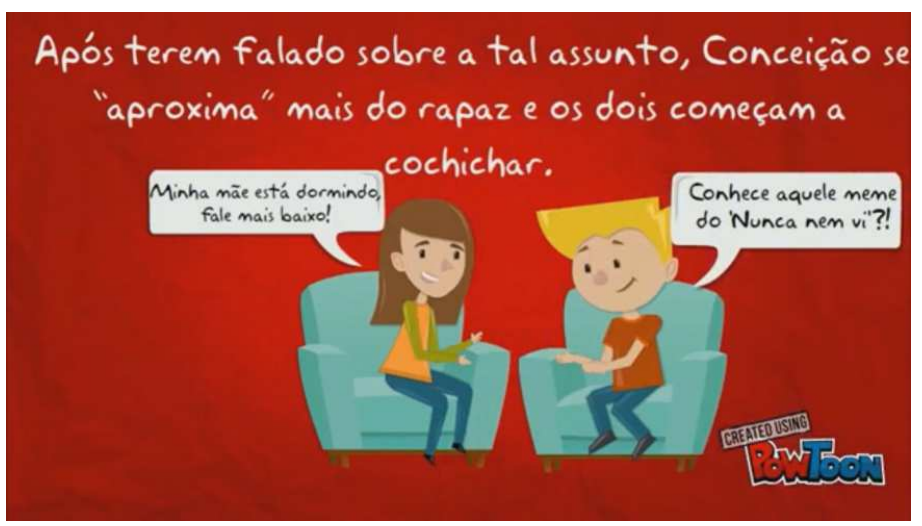

Fonte: dados da pesquisa.

Essa tela tomou como base o trecho:

Continuei a dizer o que pensava das festas da roça e da cidade, e de outras cousas que me iam vindo à boca. Falava emendando os assuntos, sem saber por que, variando deles ou tornando aos primeiros, e rindo para fazêla sorrir e ver-lhe os dentes que luziam de brancos, todos iguaizinhos. Os olhos dela não eram bem negros, mas escuros; o nariz, seco e longo, um tantinho curvo, dava-lhe ao rosto um ar interrogativo. Quando eu alteava um pouco a voz, ela reprimia-me:- Mais baixo! Mamãe pode acordar (ASSIS, 2004, p. 388).

O narrador não diz que eles conversam animadamente, mas que cochicham. Por que falam baixo? Seria apenas para que a mãe de Conceição não acordasse? São perguntas retóricas implícitas que puxam conversa com o leitor do livroclip. Isso remete a Bakhtin e Volochivov (1976) em "O discurso na vida e o discurso na arte". Os autores explicam que é preciso desvelar os enunciados, já que as palavras ditas estão impregnadas de coisas presumidas e coisas não ditas e o significado de uma enunciação nunca coincide com o conteúdo verbal, ou seja, no conteúdo explícito, está o conteúdo presumido .

Outro ponto é que substituem o tema da conversa do conto original com o intuito de possibilitar a interlocução do livroclip com o leitor contemporâneo. Nas palavras das alunas: "Conhece aquele meme do 'nunca nem vi?"

Conforme Borges e Borges (2017), a retextualização possibilita a compreensão das diferenças e das peculiaridades entre um gênero e outro na situação real de (re) elaboração, ao levar em conta as condições do produtor do texto, seus objetivos, a figura do interlocutor, as escolhas linguísticas mais adequadas à situação e as circunstâncias históricas e culturais. Nesse sentido, percebe-se que as alunas se apropriaram do papel de produtoras de linguagem, pois falam a alguém sobre o que leram, com a intenção de que as escute e as compreenda. Elas estabelecem, portanto, um processo interlocutivo entre a obra de Machado de Assis e o público leitor do livroclip.

A próxima cena, a de número 9 , constitui 0 clímax da narrativa. O clima de suspense fica mais intenso porque as autoras reconstroem mais um trecho do conto, provocando o leitor a continuar a leitura para conhecer o desfecho da narrativa. Eis o fragmento do conto machadiano:

Não estando abotoadas as mangas, caíram naturalmente, e eu vi-lhe metade dos braços, muito claros, e menos magros do que se poderiam supor. A vista não era nova para mim, posto também não fosse comum; naquele momento, porém, a impressão que tive foi grande(ASSIS, 2004,p. 388).

Figura 9: Diálogo entre Conceição e Nogueira.

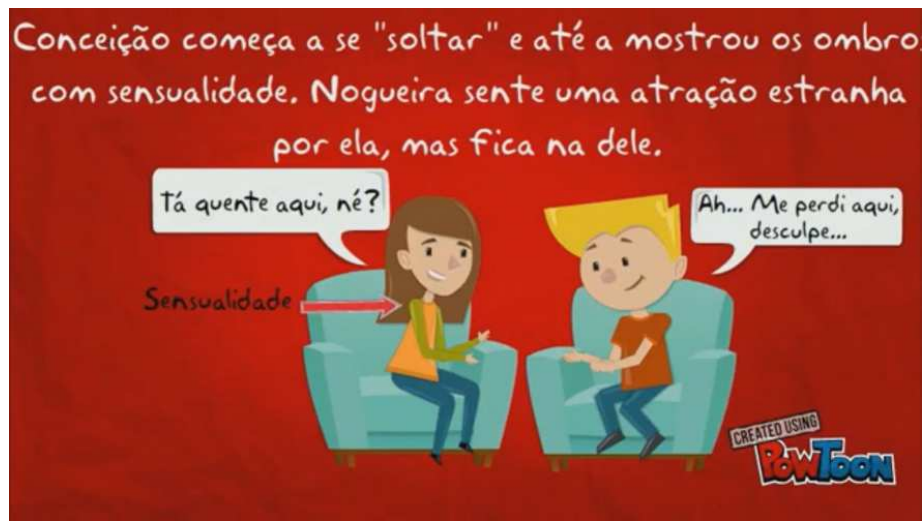

Fonte: Dados da pesquisa.

Ressaltamos o trecho narrativo: "Conceição começa a se 'soltar' e até a mostrar os ombros com sensualidade. Nogueira sente uma atração estranha por ela, mas fica na dele". Importa destacar o aspeamento empregado pelas alunas na palavra "soltar", que pode provocar interpretações como "libertar-se das convenções sociais impostas à mulher na época", ou ainda "sentir-se mais à vontade". Para produzirem esse enunciado, as alunas consideraram o papel social de Conceição, segundo elas, mas 
empregaram uma palavra do repertório vocabular dos adolescentes contemporâneos.

As falas dos personagens, associadas à seta $e$ a palavra "sensualidade" apontando para os braços de Conceição, expõem muito sobre a nudez dos braços da personagem, pois não era de bom tom que a mulher os deixasse à mostra no contexto do século XIX. Nesse sentido, é importante considerar que a plataforma PowToon possibilitou uma convergência de inúmeras linguagens num único material, pois para produzir discursos ao leitor jovem em suportes digitais não basta mais um código linguístico, é necessário que se incluam imagens, sons, animação entre outros elementos semióticos no objeto a ser lido.

Por fim, na Figura 10, as autoras rompem abruptamente o suspense anterior ao quebrar a expectativa do leitor. Em vez do final da história, elaboram perguntas com o objetivo de dialogar com o leitor contemporâneo, aproximando-o do conto-base. A intenção é provocar o leitor de tal modo que ele sinta a necessidade de ler o conto original para investigar sobre o desfecho da história.

Figura 10: Diálogo com o leitor.

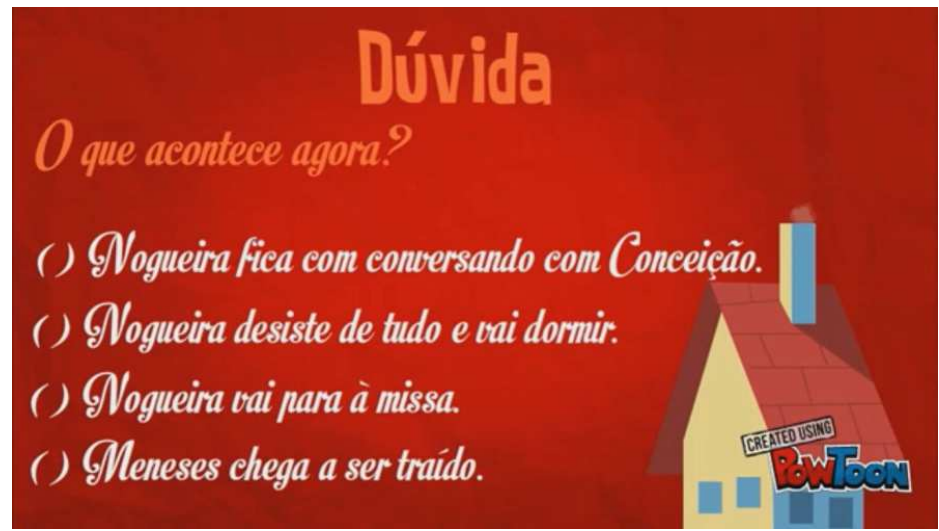

Fonte: Dados da pesquisa.

A estratégia usada pelas autoras evoca 0 dialogismo postulado por Bakhtin (2018). Para o filósofo russo, o autor de uma obra espera uma resposta do outro, daquele que o lê. Para tanto, "busca exercer uma influência didática sobre o leitor, suscitar uma apreciação crítica, influir êmulos e continuadores" (BAKHTIN 2018, p. 298). Nesse processo é inevitável que o leitor deixe de associar a atual leitura a outras informações que foram adquiridas anteriormente. Dessa forma, o comportamento responsivo ativo de um leitor diante do texto Ihe possibilita um comportamento dialógico, tais como reconhecimento e a elaboração de outros enunciados.

\section{Considerações finais}

Neste artigo relacionamos os modos de leitura aos suportes e práticas sociais na contemporaneidade. O jovem é um leitor que lê na tela, vai além da escrita linear e precisa, portanto, ter conhecimentos sobre as linguagens que compõem esses suportes para que, além de reconhecê-las, as compreenda na dimensão enunciativa. Isso porque os suportes, associados às tecnologias, propiciam novos meios para a formação de leitores multimodais e também novas formas de (re) elaboração de textos, em especial, dos literários.

Assim, ao elaborarem um livroclip - gênero constituído pela linguagem multissemiótica - as alunas, sujeitos dessa pesquisa, despertaram-se para a busca de novas e mais informações sobre o autor, sobre o contexto de produção e, até mesmo, para a leitura da obra original completa.

As alunas se apropriaram dos elementos linguísticos da multimodalidade e selecionaram as linguagens, considerando os dois contextos em que os enunciados foram construídos: o século XIX e o XXI. Nessa direção, Dionísio (2006) defende que os textos multimodais e a produção de sentido só podem ser explorados dentro de um contexto social, já que "Imagem e palavra mantêm uma relação cada vez mais próxima, cada vez mais integrada" (DIONÍSIO, 2006, p. 131)

Um dos desafios da escola na atualidade é capacitar os alunos para a leitura e a construção de textos multimodais que circulam dentro e fora da escola. Nesse sentido, acreditamos que o livroclip (re) elaborado pelas alunas contribuiu para a apropriação de um gênero multimodal e despertou a atenção para uma obra clássica. Isso se tornou possível por meio do diálogo entre as leitoras-autoras e o conto machadiano Missa do Galo. 


\section{Referências}

ARENA, D. B. A. As metaformoses dos modos de ler: da rua para a escola. Passages de Paris 10 (2015) 114-12.

ASSIS, J. M. M. Contos: uma antologia - vol. II. São Paulo: Companhia das Letras, 2004. 2 ed. p. 386393.

BAKHTIN, M. Estética da criação verbal. São Paulo: WMF Martins Fontes, 2018.

BAKHTIN, M. M.; VOLOSHINOV, V. N. Discourse in life and discourse in art - concerning sociological poetics. Trad. de Carlos Alberto Faraco e Cristóvão Tezza. In: VOLOSHINOV, V. N. Freudism. New York: Academic Press, 1976.

BITENCOURTO, A. R.; DELGADO, H. O. K. O livroclip e a literatura: a mistura da tecnologia e da leitura. Seminário interinstitucional de ensino, pesquisa e extensão. Cruz Alta: Unicruz, 2011.

BORGES, J., F., B.; BORGES, R., C. A palavra é retextualizar: um trabalho com gêneros textuais na escola. Cadernos de pesquisa, vol 47, $\mathrm{n} 33$. P. 1266 a 1324, 2017.

CANI, J. B.; COSCARELLI, C. V.. Textos multimodais como objetos de ensino: reflexões em propostas didáticas. In: KERSCH, D. F.; COSCARELLI, C. V.; CANI, J. B. (ORG.). Multiletramentos e Multimodalidade: ações pedagógicas aplicadas à linguagem. São Paulo: Pontes, 2016.

COMPAGNON, A. O demônio da teoria: Literatura e senso comum. Trad. CleoniceMourão e Consuelo Santiago. Belo Horizonte: UFMG, 2001.

COUTO, R. L. D. M.; HELBEL, D. F. A leitura e sua função social: traçando perfil de leitores. In: SUNIGA, C. Práticas de leitura na escola: alguns estudos. Rolim de Moura: D'Press Editora, 2014, p. 73-83.

DELL'ISOLA, R. L. P. Retextualização de gêneros escritos. Rio de Janeiro: Lucerna, 2007.
DINIZ, I. C. S.; GRANDE, K. C. P. Livroclip da Obra Dom Casmurro, de Machado de Assis: semiótica, literatura e hipermídia. Entretextos, Londrina, v.13, n02, p.147-166, jul./dez. 2013.

DIONÍSIO,A.P.Multimodalidade discursiva na atividade oral e escrita. In: MARCUSCHI, L. A.; DIONISIO, A. P. (Org.). Fala e Escrita. Belo Horizonte: Autêntica, 2005.

DIONíSIO, A. P. Gêneros multimodais e multiletramento. In: KARWOSKI, A. M.; GAYDECZKA, B.; BRITO, K. (Orgs.). Gêneros textuais: reflexões e ensino. 3. Ed. ver. Rio de Janeiro: Nova Fronteira, 2006.

GERALDI, J. W. Portos de passagem. São Paulo: Martins Fontes, 2003.

KRESS, G. R. e van LEEUWEN, T. Reading Images: a Grammar of Visual Design. Londres: Routledge, 1996.

MARTINS, I. A literatura no ensino médio: quais os desafios do professor?. In: BUNZEN, C.; MENDONÇA, M. (Org.). Português no ensino médio e formação do professor. São Paulo: Parábola Editorial, 2006. 3ª ed. junho de 2009.

SARAIVA,J. I. A. A sedução das narrativas aplicada ao estudo de contos machadianos. In: BARBOSA, V. K.; SCHNEIDER, S. D. (Orgs.). Linguagem, sociedade e interação: reflexões teórico-práticas. Novo Hamburgo: Feevale, 2007, p.171-184.

SILVA. S. E. C. Clássicos da literatura brasileira no formato de livroclip: (re)leitura e interatividade. Texto livre, linguagem e tecnologia, 2015, vol8, n.1.

ZILBERMAN. R. Fim dos livros, fim dos leitores? São Paulo: Senac, 2001.

\section{COMO CITAR ESSE ARTIGO}

HELBEL, Dioneia Foschiani; COUTO, Regiani Leal Dalla Martha; SILVA, Sônia Carla Gravena Cândido da. O gênero discursivo livroclip: diálogos entre o conto machadiano e o jovem leitor contemporâneo. Signo, Santa Cruz do Sul, v. 44, n. 80, p. 183-193, ago. 2019. ISSN 1982-2014. Disponível em: $<$ https://online.unisc.br/seer/index.php/signo/article/view/13370>. Acesso em: doi: https://doi.org/10.17058/signo.v44i80.13370. 